\title{
Architectural properties of the musculoskeletal system in the shoulder of two callitrichid primate species derived from virtual dissection
}

\author{
Lennart Eigen $^{1}\left[\right.$ ] John A. Nyakatura ${ }^{1}$
}

Received: 28 October 2020 / Accepted: 6 May 2021 / Published online: 28 June 2021

(c) The Author(s) 2021

\begin{abstract}
Callitrichidae are small, arboreal New World primates that utilize a variety of locomotor behaviors including trunk-to-trunk leaping (TTL) and horizontal locomotion which involve differential functional demands. Little is known about the relationship between the preferred locomotor behavior and musculoskeletal architecture of these primates. In this study, we compared the musculoskeletal architecture of selected shoulder muscles in two cadavers each of the trunk-to-trunk leaper Cebuella pygmaea and the mainly pronograde quadrupedally moving Saguinus imperator subgrisescens. Contrast-enhanced microfocus computed tomography $(\mu \mathrm{CT})$ was used to virtually dissect the cadavers, produce muscle maps, and create 3D reconstructions for an image-based analysis of the muscles. Muscle lengths, muscle volumes, and osteological muscle moment arms were measured, and the anatomical cross-sectional areas (ACSA) were calculated. We expected the muscles of the forelimb of S. imperator to be larger in volume and to be relatively shorter with a larger ACSA due to a higher demand for powerful extension in the forelimbs of this horizontally locomoting species. For $C$. pygmaea, we expected relatively larger moment arms for the triceps brachii, supraspinatus, infraspinatus and subscapularis, as larger moment arms present an advantage for extensive vertical clinging on the trunk. The muscles of $S$. imperator were relatively larger in volume than in $C$. pygmaea and had a relatively larger ACSA. Thus, the shoulder muscles of $S$. imperator were suited to generate relatively larger forces than those of $C$. pygmaea. Contrary to our expectations, there were only slight differences between species in regard to muscle lengths and moment arms, which suggests that these properties are not dependent on the preferred locomotor mode. The study of this limited dataset demonstrates that some but not all properties of the musculoskeletal architecture reflect the preferred locomotor behavior in the two species of Callitrichidae examined.
\end{abstract}

Keywords ACSA $\cdot$ Muscle architecture $\cdot$ Muscle moment arm $\cdot$ Muscle maps $\cdot$ Callitrichidae

\section{Introduction}

The adaptation of an organism to different lifestyles is often reflected in its anatomy. Thus, investigating the anatomy quantitatively and qualitatively in a comparative framework can provide information about the adaptations of organisms to their respective environments. With the help of 3D visualization and digital analysis, advancements in imaging methods have made possible an image-based examination of the soft tissues that critically contribute to the musculoskeletal system (Metscher 2009a; Pauwels et al. 2013; Descamps

Lennart Eigen

lennart.eigen@hu-berlin.de

1 Comparative Zoology, Institute of Biology, Humboldt University of Berlin, Philippstraße 13, 10115 Berlin, Germany et al. 2014). The musculoskeletal architecture has a significant influence on function (Lieber et al. 1992). This also includes the internal structure of a muscle as well as parameters that describe the effect of the muscles on the skeleton, such as the moment arms of a muscle to a joint. Forelimb osteological differences have been demonstrated to reflect differences in locomotor behavior (e.g., Fleagle and Meldrum 1988; Larson 2015; Wölfer et al. 2019). In addition to the osteological properties, limb function is obviously determined by muscle properties, such as force-generating capacity and contraction speed and distance, which are determined by muscle architecture (e.g., Gans and Bock 1965; Lieber et al. 1992; Lieber and Fridén 2000; Michilsens et al. 2009; Allen et al. 2010; Kikuchi 2010; Rosin and Nyakatura 2017; Marchi et al. 2018; Olson et al. 2018; Taverne et al. 2018; Nyakatura et al. 2019; Regnault et al. 2020). 


\section{Muscle architectural properties}

Studies of the variation in limb muscle anatomy in primates have shown that limb muscles of different species differ depending on the preferred locomotor behavior and body size (e.g., Demes et al. 1998; Leischner et al. 2018). Muscle architecture is defined as the three-dimensional arrangement of the muscle fibers within a muscle (Lieber et al. 1992). The architecture of a muscle is by and large consistent between individuals of the same species (Lieber and Fridén 2001). As a result, the quantification of the parameters of the muscles is crucial for the interpretation of anatomical adaptations and specializations.

There is a fundamental trade-off in the architecture of a muscle. For a given volume, muscles can be fast (a few long muscle fibers) or powerful (many short muscle fibers) (Zajac 1992; Allen et al. 2010; Kikuchi 2010; Rosin and Nyakatura 2017). In order for a muscle to generate more force, either the volume must be increased, or the muscle architecture must be changed accordingly (Allen et al. 2010). In muscles of the same volume, an "in-series" arrangement of fibers has a greater potential to contract, since the contraction potential is proportional to the number of contractile units along the line of action (Lieber and Fridén 2001; Allen et al. 2010). The length of the muscle fiber bundles, the fascicles, thus reflects the working area of a muscle (Rosin and Nyakatura 2017). They also have a greater potential to move faster, as each muscle fiber theoretically contracts at the same speed and potentially at the same time, and longer muscle fibers can thus span a greater distance in a given time (Zajac and Gordon 1989; Zajac 1992; Leischner et al. 2018). Force-generating capacity of a muscle is usually derived in anatomical studies from physiological cross-sectional area (PCSA), which has been shown to be a good indicator of force-generating capacity (e.g., Zajac and Gordon 1989; Zajac 1992; Kikuchi 2010; Rosin and Nyakatura 2017). It can be calculated from the pennation, i.e., the angle of the muscle fibers' long axes from the muscle's line of action, muscle mass, and muscle density (q) (1.06 g/ $\left.\mathrm{cm}^{3}\right)$ (Méndez 1960; Kikuchi 2010). The PCSA provides a better prediction of the strength of a muscle than the volume (i.e., the mass) of a muscle (Payne et al. 2006; Leischner et al. 2018). Muscles with a large PCSA have a large number of fascicles arranged in parallel, resulting in a large number of fibers acting simultaneously to generate force. In the current study, we were not able to determine fascicle length and pennation angle from microfocus computed tomography $(\mu \mathrm{CT})$ data; thus the anatomical cross-sectional area (ACSA) was quantified as an alternative. The ACSA sets the volume of a muscle in relation to its length without taking the pennation angle and fascicle length into account. As an indicator of force generation, it is therefore less accurate than the PCSA. Still, the larger the ACSA, the more likely this muscle is adapted to movements that require great force (Ikai and Fukunaga 1968). If a muscle is required to contract both powerfully and quickly over a longer distance, then it must have a larger volume than those that are only specialized for either larger or more powerful contractions (Anapol and Barry 1996).

\section{Muscle moment arms}

The moment arm converts the force generated by the muscle into a torque that causes the skeletal element to rotate around a joint. It thus often reflects its role, for example as a stabilizer or prime mover (Ackland et al. 2008). Comparative studies on moment arms, for example, succeeded in identifying specializations of the musculoskeletal system regarding locomotor or masticatory behaviors (e.g., Michilsens et al. 2009; Channon et al. 2010; Regnault et al. 2017). It was shown that the moment arm of the hindlimb muscles in gibbons are adapted to the locomotor demands. Their hip and knee extensors have larger muscles with shorter fascicles and relatively smaller moment arms. This functional adaptation enables rapid joint rotation with powerful movements that are required for certain locomotor tasks such as climbing and leaping (Channon et al. 2010). A distinction can be made between the instantaneous muscle moment arm and the osteological muscle moment arm (here abbreviated as OMMA) (Fig. 1). The instantaneous muscle moment arm is

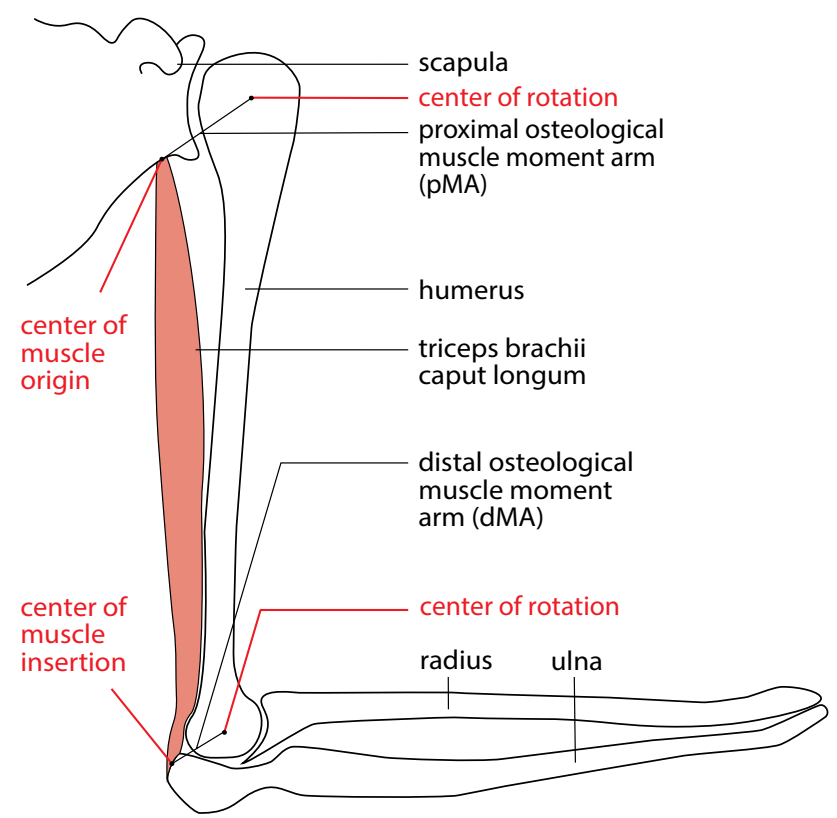

Fig. 1 Schematic illustration of the distal (dMA) and proximal (pMA) osteological muscle moment arm (OMMA) exemplarily for triceps brachii caput longum 
defined as the perpendicular distance from a muscle's line of action to the skeletal element's center of rotation (Cartmill et al. 1985; Ackland et al. 2008; Williams et al. 2008). The OMMA is a measure of the distance between the center of rotation of the joint and the attachment point of the muscle (Murray et al. 2002). In our analysis, we chose the OMMA because it does not depend on the instantaneous joint position. By using a 3D model based on a $\mu \mathrm{CT}$ scan, it is possible to measure the distance between muscle attachment points and the center of rotation directly.

\section{Callitrichid primate locomotion}

Callitrichidae belong to the New World monkeys. Their range extends from northern Bolivia to Panama (Buckner et al. 2015), and they differ, among other things, in their habitat use and preferred mode of locomotion (e.g., Garber and Pruetz 1995; Nadjafzadeh and Heymann 2008; Nyakatura and Heymann 2010). Studies of the locomotor behavior of diverse Callitrichidae show that species that inhabit different layers of a forest are specialized in different movement patterns (Garber and Pruetz 1995), which has led to the evolution of a differentiated musculoskeletal anatomy (Fleagle and Mittermeier 1980; Hunt et al. 1996). Two main modes of preferred leaping behavior have been described within the Callitrichidae (Prost 1965): horizontal leaping (HL) and vertical clinging and leaping, which is similar to trunk-to-trunk leaping (TTL) performed by $C$. pygmaea. Callitrichidae that specialize in HL usually move in a pronograde posture mainly on horizontal and oblique, often terminal branches and leap from these supports onto the next horizontal, terminal branch (Schmidt 2011). The locomotor behavior of most tamarins is largely characterized by $\mathrm{HL}$ as they move through the rainforest through a series of long, acrobatic jumps that usually start and end on very thin branches (Garber 1980). They mostly avoid vertical surfaces (Garber 1980). As a representative of this type of locomotion, Saguinus imperator subgrisescens (the bearded emperor tamarin, S. imperator (SIS) for brevity) is examined in this study. With an average body mass of $475 \mathrm{~g}$, S. imperator belongs to the medium-sized New World Monkeys (Peres 1993; Smith and Jungers 1997). Horizontal leaping (32\%) and walking (34\%) are the dominant modes of locomotion in S. imperator. Other important behaviors but which are not used as frequently are claw climbing (12\%) and bounding (8\%) (Karantanis 2010). Saguinus imperator use oblique supports (50\%) more often than horizontal supports (35\%), and use vertical supports (15\%) the least (Buchanan-Smith et al. 2000).

Trunk-to-trunk leaping is unusual for tamarins and is more likely to be observed in marmosets, especially in smaller representatives (e.g., Fleagle and Mittermeier 1980; Garber 1980, 1991; Garber and Sussman 1984; Stafford et al. 1994; Garber and Pruetz 1995; Youlatos 1999). In TTL, the monkeys leap from a vertical position from one trunk to another one and also lands in a vertical position (Youlatos 1999). This positional behavior can be observed in Cebuella pygmaea (pygmy marmoset), the second species examined here. Cebuella pygmaea (CP) is the smallest member of the Callitrichidae, with an average body mass of just $150 \mathrm{~g}$, and field studies show that $C$. pygmaea uses claw climbing, clinging, and vertical surfaces more than any other representative of the Callitrichidae (Youlatos 2009). Nevertheless, a large repertoire of locomotor behavior can be observed in C. pygmaea, too, including horizontal walking and running as well as horizontal leaping between branches and other surfaces. Climbing (28\%) was the most common behavior, followed by walking (23\%) (Karantanis 2010). Cebuella pygmaea use vertical supports (55\%) most of the time. Oblique supports (27\%) are utilized less and horizontal supports (18\%) the least (Buchanan-Smith et al. 2000). However, of all leaps, $85 \%$ have been documented to be from or to a vertical underground (Kinzey et al. 1975). The prevalence of locomotion on vertical supports is typical of $C$. pygmaea, since they feed more often on vertical supports and cling onto trunks while feeding on exudates (Youlatos 1999; Karantanis 2010).

\section{Expected differences in shoulder and brachial anatomy and aim of this study}

The cadaveric samples of two species (a total of four specimens) were stained and then scanned with a $\mu \mathrm{CT}$ scanner. Three-dimensional reconstruction of shoulder and brachial muscles was used to assess muscle volume, muscle lengths, osteological muscle moment arms (OMMA), and anatomical cross-sectional area (ACSA) to test for expected anatomical differences that potentially reflect adaptations to differing functional demands induced by diverging locomotor behavior.

We examined the musculoskeletal system of a limited dataset of these two primates, which differ in their preferred mode of locomotion (e.g., Fleagle and Mittermeier 1980; Garber 1980, 1991; Youlatos 1999, 2009), using contrast-enhanced $\mu \mathrm{CT}$. We expected that these differences in locomotor behavior are reflected in the anatomy of the two species. We focused on the intrinsic muscles that span the shoulder joint and muscles of the upper arm in our attempt to identify potential adaptations in the musculoskeletal system. Eight different muscles were examined ( $n=32$ muscles in total). These included $\mathrm{m}$. biceps brachii, $\mathrm{m}$. triceps brachii, $\mathrm{m}$. brachialis, m. deltoideus, $m$. supraspinatus, $m$. infraspinatus, $m$. teres major, and $\mathrm{m}$. subscapularis. The infraspinatus, supraspinatus, and subscapularis are part of the rotator cuff and important for the stabilization of the shoulder joint (Roberts 
1974). Teres major is responsible for humeral retraction (Larson and Stern 1986, 2013). The supraspinatus assists the deltoideus in providing the force for elevation of the arm. The infraspinatus depresses the humeral head, ensuring that the humerus is not displaced but rather raised (Larson and Stern 1986). Biceps brachii and brachialis are elbow flexors; triceps brachii is an elbow extensor and a humerus retractor (Rupert et al. 2015). Elbow flexion and extension, and limb extension are important in arboreal locomotion, because to maintain balance, arboreal species need to rotate the forelimb forcefully (Larson and Stern 2006).

For S. imperator we expected relatively shorter muscles with a larger volume in relation to body size, since larger primates generally have relatively more powerful muscles in the forelimbs than smaller primates (Leischner et al. 2018). Since in HL the forelimbs can be expected to substantially contribute to body propulsion via humerus retraction (Schmitt 2003; Hesse et al. 2015), we expected relatively larger force-generating capacity as reflected in a relatively larger ACSA than in the TTL species. Primates such as $C$. pygmaea, that use TTL, are expected to have relatively long muscles with low volume in the forelimb compared to primates that prefer HL (Leischner et al. 2018). This might be an indicator of large muscle contraction distances and high contraction speeds which are important components of locomotion in a vertical clinging position (Huq et al. 2015; Leischner et al. 2018). We also expected relatively larger moment arms in the TTL species, which involves vertical clawing on tree trunks over a long period of time, and this holding should be reflected in an anatomy that favors torque generation without the need for the constant generation of large muscle forces.

\section{Materials and methods}

One male and one female of each species $S$. imperator (SIS) and C. pygmaea (CP) were provided frozen and without internal organs by the Antwerp Zoo (Royal Zoological Society of Antwerp), where they lived in a group. The age of the animals is known (Table 1). After thawing the carcasses for one day, the head-torso length was measured, the body mass (excluding the inner organs) was determined, and finally they were skinned. The animals were fixed to kebab skewers with cable ties and then immersed in formaldehyde (ROTI-Histofix 4\%; acid-free (pH7) phosphate-buffered formaldehyde solution 4\%) for 9 or 17 days (Table 1). Next, specimens were immersed in successive alcohol baths of increasing concentration. The animals were treated as follows: $1 \mathrm{~h}$ in a water bath, $1 \mathrm{~h}$ in $15 \%$ ethanol, $1 \mathrm{~h}$ in $30 \%$ ethanol, $1 \mathrm{~h}$ in 50\% ethanol, $1 \mathrm{~h}$ in 60\% ethanol, and $1 \mathrm{~h}$ in $70 \%$ ethanol (Metscher 2009a, b; Pauwels et al. 2013; Descamps et al. 2014). The last step is staining with PTA (3\% (w/v) phosphotungstic acid in 70\% ethanol), which serves as the contrast medium for subsequent $\mu \mathrm{CT}$ scans (Koç et al. 2019).

The shoulders of $S$. imperator and $C$. pygmaea were scanned at the Museum für Naturkunde Berlin with a YXLON FF35 CT (YXLON International GmbH, Hamburg, Germany). A helix scan with a detector time of $0.8 \mathrm{~s}$ was carried out on all objects. For both specimens of $C$. pygmaea, 1886 image slices with a voxel size of $0.0324 \times 0.0324 \times 0.0324 \mathrm{~mm}$ made up the image stack. The scan parameters were $135 \mu \mathrm{A}$ and $170 \mathrm{kV}$. For S. imperator 1965 images made up the complete stack. For SIS1 the voxel size is $0.0413 \times 0.0413 \times 0.0413 \mathrm{~mm}$; for SIS2 it is $0.0456 \times 0.0456 \times 0.0456 \mathrm{~mm}$. The scan parameters were $135 \mu \mathrm{A}$ and $180 \mathrm{kV}$.

For the segmentation of muscles and bones and labeling as well as the calculation of the volumes, AMIRA software
Table 1 Samples and staining protocol of samples with phosphotungstic acid (PTA)

\begin{tabular}{lllll}
\hline Species & S. imperator & S. imperator & C pygmaea & C pygmaea \\
\hline Identification & M10981 & M10924 & M10029 & M11128 \\
Abbreviation & SIS1 & SIS2 & CP1 & CP2 \\
Head/trunk length (mm) & 230 & 235 & 120 & 140 \\
Length of hind limb (mm) & 120 & 125 & 80 & 85 \\
Length of front limb (mm) & 70 & 85 & 70 & 72 \\
Eviscerated body mass $(\mathrm{g})$ & 348 & 262 & 60 & 50 \\
Age (years) & 15 & 7 & 2 & 5 \\
Sex & Female & Male & Female & Male \\
Staining & & & & \\
Formaldehyde & 9 days & 2 days & 17 days & 2 days \\
0.3\% PTA & 18 days & - & 18 days & - \\
3\% PTA & 15 days & 15 days & 15 days & 15 days \\
3\% PTA (refreshed) & 14 days & 14 days & 14 days & 14 days
\end{tabular}




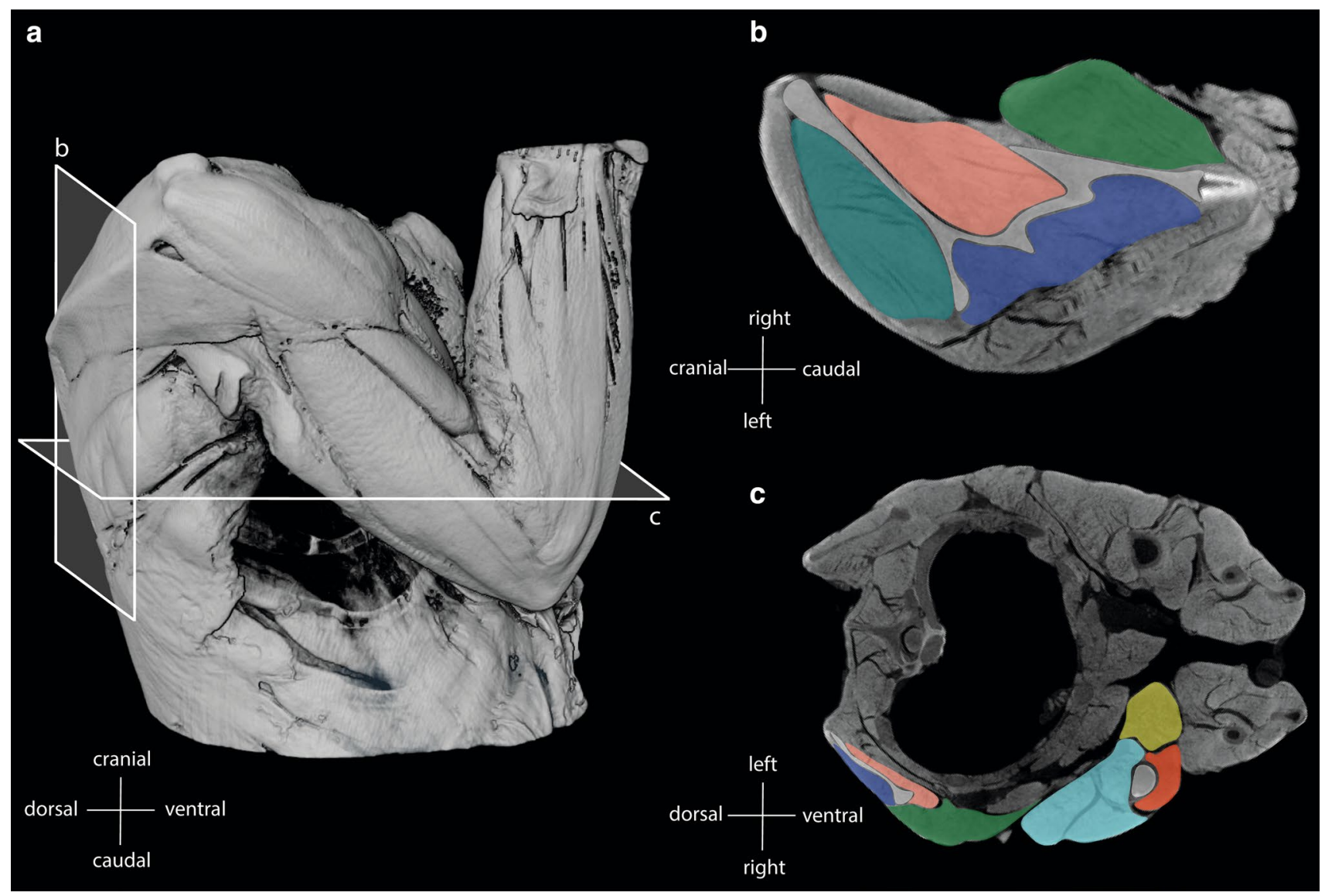

Fig. 2 a Lateral view of the right shoulder of S. imperator (SIS1); b frontal plane cross-section as shown in a; $\mathbf{c}$ transverse plane crosssection as shown in a; biceps brachii: yellow; triceps brachii: tur- quoise; brachialis: red; supraspinatus: dark turquoise; infraspinatus: blue; teres major: dark green; subscapularis: pink

insertion of a muscle and the center of the joint on which the muscle acts. The proximal moment arm (pMA), on the other hand, is the distance between the center of the origin of a muscle and the center of the joint it acts on (Fig. 1).

After measuring the muscle lengths and the distal and the proximal OMMA, the skeletal element of each moment arm was measured. With the determined length and volume of the muscles, the ACSA was calculated using the following formula (Schumacher 1961):

\section{ACSA $=$ Volume $/$ Length}

In addition to the absolute values, we compared the muscle volume, length, and the ACSA in relation to the average body mass of the corresponding species. To account for the differences in size, the muscle volume (muscle volume/body mass), muscle length (muscle length/body mass ${ }^{0.33}$ ), and ACSA (ACSA/body mass ${ }^{0.66}$ ) were standardized by average body mass under the assumption of isometric scaling (Allen et al. 2010). Moment arms are standardized by the length of the respective connecting skeletal element. The average mass 
for S. imperator is $475 \mathrm{~g}$ (Smith and Jungers 1997) and for $C$. pygmaea $150 \mathrm{~g}$ (Youlatos 2009).

\section{Results}

\section{Muscle topology}

Overall, the muscle attachment areas are similar in both species examined. However, there are also some differences. Biceps brachii caput longum originates at the tuberculum supraglenoidale. The origin of biceps brachii caput breve is at the processus coracoideus. The insertion of biceps brachii is at the tuberositas radii. The origin area of triceps brachii caput longum is at the tuberculum infraglenoidale and has approximately the same size in both species (Fig. 3). The origin area for triceps brachii caput mediale and laterale is at the facies posterior of the humerus and is relatively larger in $S$. imperator than in $C$. pygmaea (Fig. 4). The relative size of the insertion area for triceps brachii is at the olecranon and has approximately the same size in both species (Fig. 5). The brachialis
Fig. 3 Muscle maps of the shoulder musculature attaching to the scapula. a $S$. imperator $\mathbf{b}$ C. pygmaea; left: lateral view of a right scapula; right: medial view of a right scapula. Scale $\mathrm{bar}=10 \mathrm{~mm}$
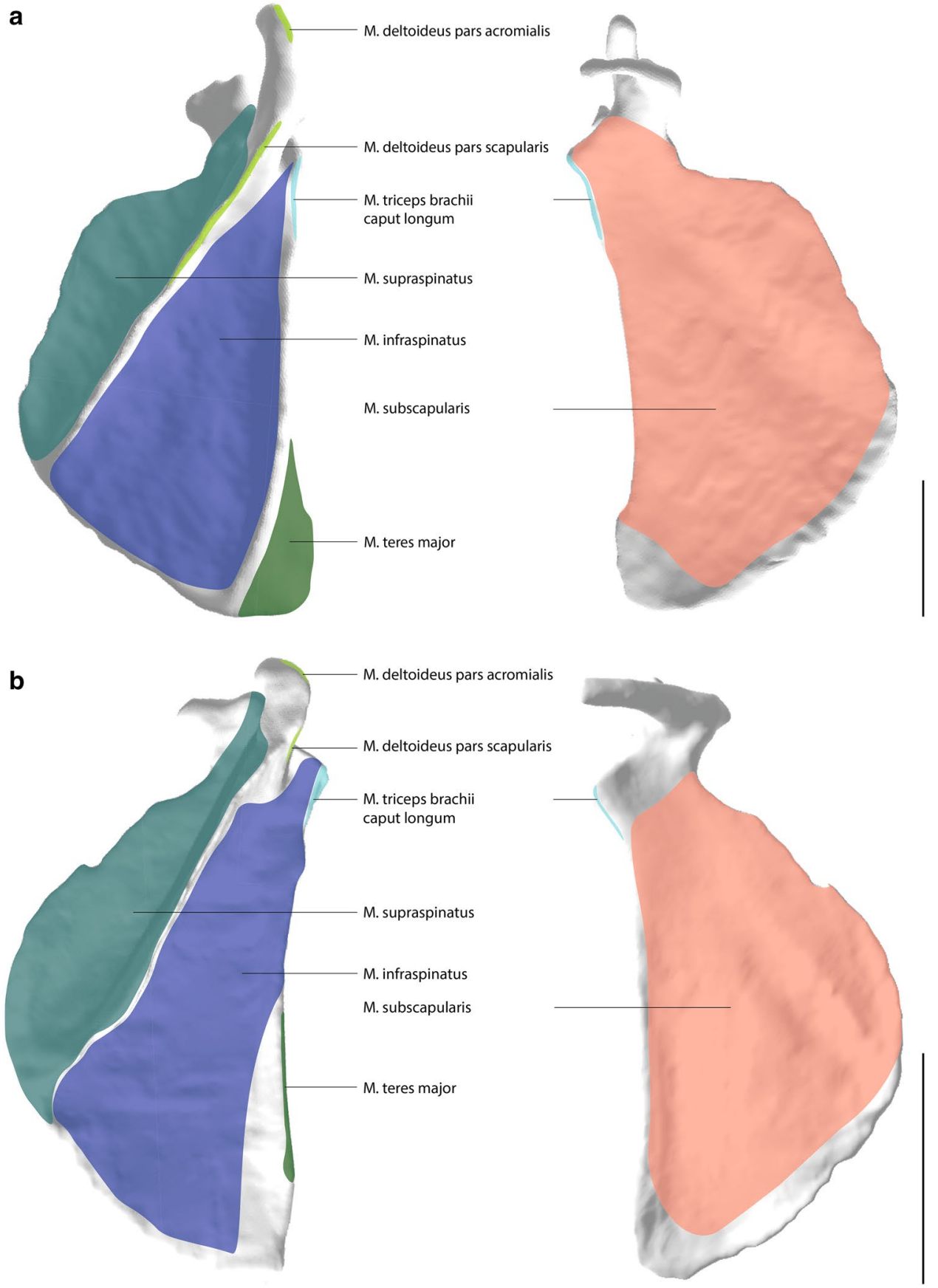
Fig. 4 Muscle maps of the shoulder musculature attaching to the scapula. a $S$. imperator $\mathbf{b}$ C. pygmaea; left: lateral view of a right humerus; right: medial view of a right humerus. Scale bar $=10 \mathrm{~mm}$ a

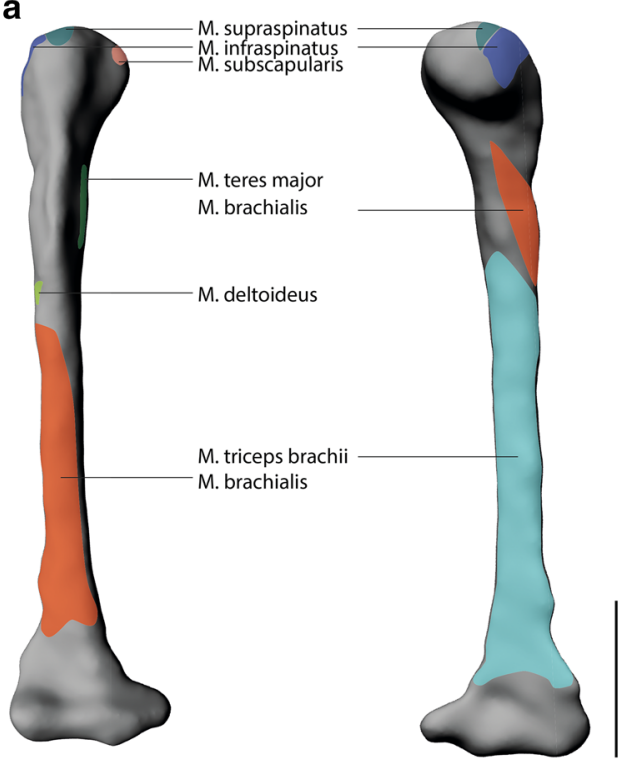

b

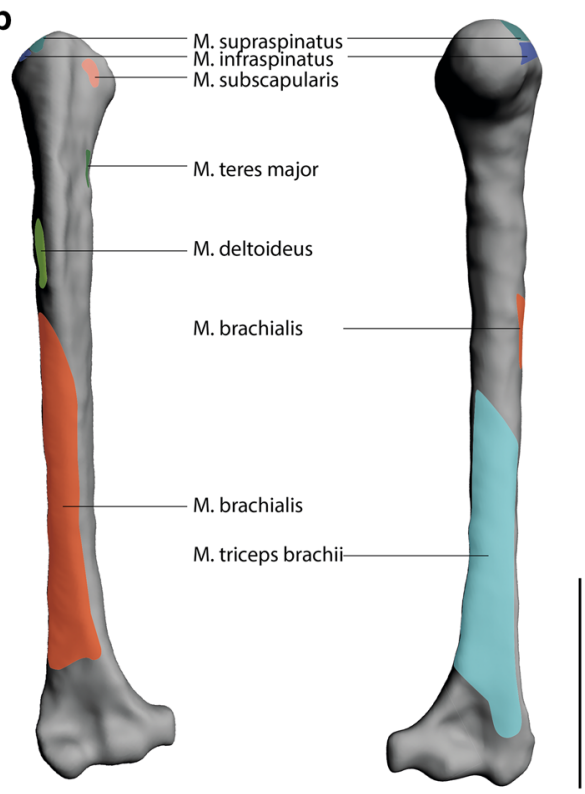

b

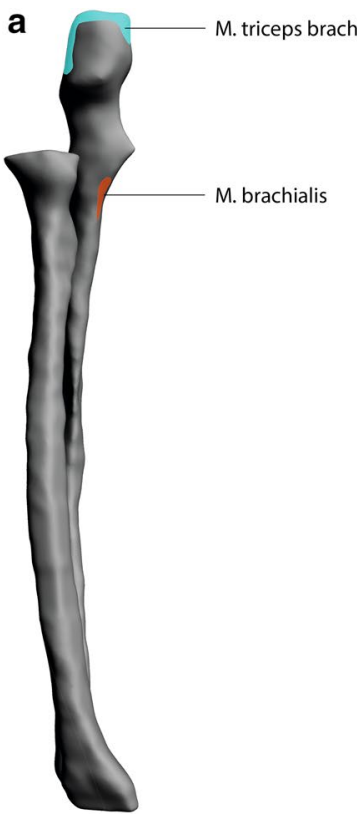

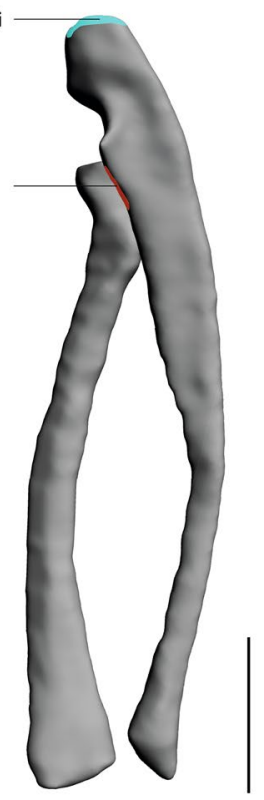

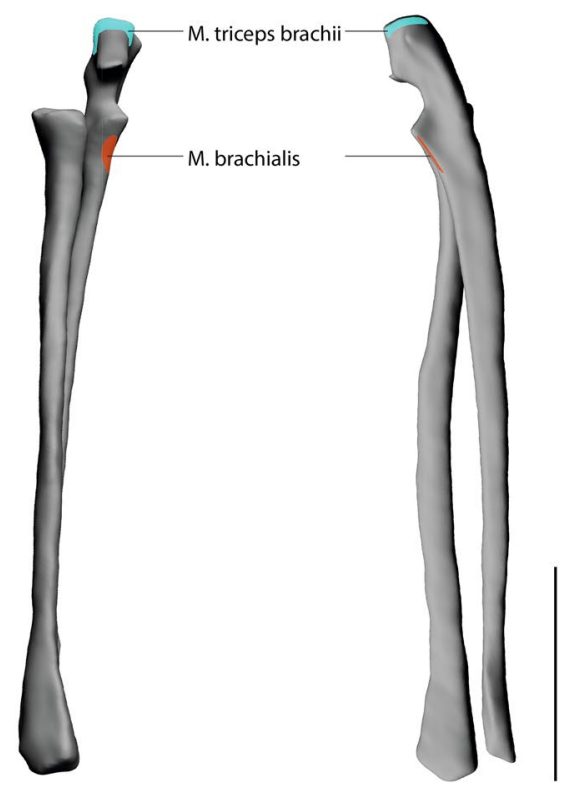

Fig. 5 Muscle maps of the musculature attaching to the radius und ulna. a $S$. imperator $\mathbf{b}$ C. pygmaea; left: lateral view of a right radius and ulna; right: medial view of a right radius and ulna. Scale bar $=10 \mathrm{~mm}$ originates at the facies anterior of the humerus, and the relative size of its attachment area is one and a half times larger in S. imperator than in C. pygmaea (Fig. 4). The insertion area for brachialis is at the tuberositas ulnae and has approximately the same relative size in both species (Fig. 5). Deltoideus pars acromialis originates at the acromium and the origin area is relatively the same size in both species. Deltoideus pars scapularis has its origin on the spina scapulae and the attachment area is three times larger in S. imperator than in C. pygmaea (Fig. 3). Deltoideus pars clavicularis has its origin in the acromial third of the clavicle. In S. imperator, the attachment area of this muscle is three times larger than in C. pygmaea (Fig. 6). The insertion of deltoideus in both species is on the tuberositas deltoidea (Fig. 4). The teres major originates at the margo lateralis and the attachment area is relatively larger in S. imperator compared to C. pygmaea (Fig. 3). The insertion of teres major is at the crista tuberculi and relatively smaller in $C$. pygmaea compared to $S$. imperator (Fig. 4). The origin of infraspinatus is at the fossa infraspinata and the attachment area is relatively slightly larger in S. imperator than in C. pygmaea (Fig. 3). The insertion area of infraspinatus is at the caput humeri and relatively larger in S. imperator (Fig. 4). The supraspinatus 
Fig. 6 Muscle maps of the shoulder musculature attaching to the clavicula. a $S$. imperator b C. pygmaea; left: lateral view of a right clavicula; right: medial view of a right clavicula. Scale bar $=10 \mathrm{~mm}$ a

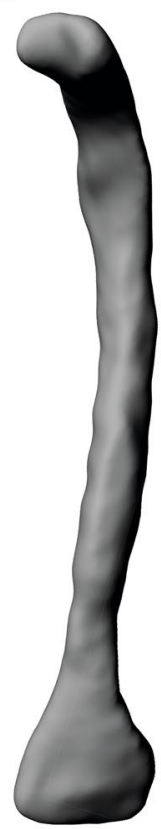

b

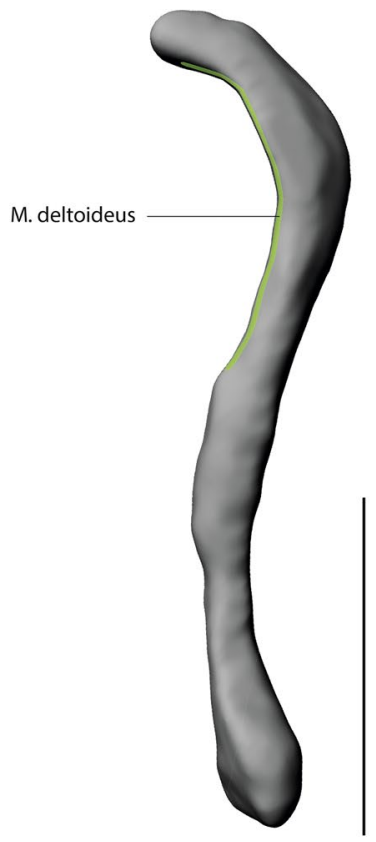

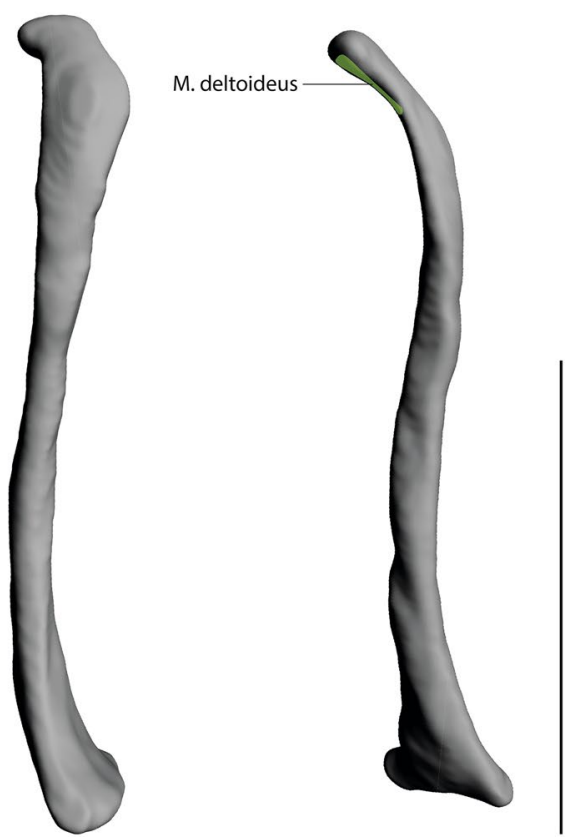

Table 2 Muscle volume in $\mathrm{mm}^{3}$ (MV) and in relation to the average body mass of the corresponding species $\left(\mathrm{MV}_{\text {rel }}\right)$

\begin{tabular}{llrrrr}
\hline Muscle & & \multicolumn{1}{c}{ SIS1 } & \multicolumn{1}{c}{ SIS2 } & CP1 & CP2* \\
\hline Biceps brachii & MV & 701.89 & 370.89 & 158.95 & 45.08 \\
& $\mathrm{MV}_{\text {rel }}$ & 1.48 & 0.78 & 1.06 & 0.30 \\
Triceps brachii & $\mathrm{MV}$ & 2430.11 & 1415.65 & 329.64 & 171.85 \\
& $\mathrm{MV}$ rel & 5.12 & 2.98 & 2.20 & 1.15 \\
Brachialis & $\mathrm{MV}$ & 318.53 & 204.82 & 48.03 & 31.84 \\
& $\mathrm{MV}$ & 0.67 & 0.43 & 0.32 & 0.21 \\
Deltoideus & $\mathrm{MV}$ & 759.91 & 454.55 & 66.27 & 34.69 \\
& $\mathrm{MV}$ rel & 1.60 & 0.96 & 0.44 & 0.23 \\
Teres major & $\mathrm{MV}$ & 662.91 & 427.26 & 133.04 & 27.94 \\
& $\mathrm{MV}$ & 1.40 & 0.90 & 0.89 & 0.19 \\
Supraspinatus & $\mathrm{MV}$ & 583.04 & 378.72 & 89.80 & 44.31 \\
& $\mathrm{MV}$ rel & 1.23 & 0.80 & 0.60 & 0.30 \\
Infraspinatus & $\mathrm{MV}$ & 614.10 & 365.46 & 118.25 & 41.33 \\
& $\mathrm{MV}_{\text {rel }}$ & 1.29 & 0.77 & 0.79 & 0.28 \\
Subscapularis & $\mathrm{MV}$ & 975.73 & 533.47 & 153.70 & 117.94 \\
& $\mathrm{MV}_{\text {rel }}$ & 2.05 & 1.12 & 1.02 & 0.79 \\
\hline
\end{tabular}

*Atrophied specimen marked with an asterisk

originates at the fossa supraspinata and the attachment area is relatively the same size in both species (Fig. 3). The insertion area of supraspinatus is at the caput humerus and has approximately the same relative size in both species (Fig. 4). The subscapularis originates at the fossa scapularis and the relative size of the attachment area is the same in both species (Fig. 3). The insertion area is at the tuberculum minus and has relatively the same size in both species (Fig. 4).

\section{Muscle volume}

Absolute values for muscle volume for the four specimens analyzed can be found in Table 2. The relative volume of the triceps brachii, the brachialis, the deltoideus, and the supraspinatus is approximately twice as large in CP1 as in CP2 (Figs. 7, 8, 9). Similarly, the biceps brachii and the teres major are four times larger, and the subscapularis is one and a half times larger in CP1 than in CP2. The relative volume for all muscles considered is one and a half times larger in SIS1 than in SIS2. The relative muscle volume of $S$. imperator is larger than that of C. pygmaea.

\section{Muscle length}

Absolute values for muscle length for the four specimens analyzed can be found in Table 3 . The two specimens of each species in our limited dataset did not exhibit pronounced differences. The specimens representing the same species did not show distinct differences in relative muscle length (Fig. 7). The relative muscle length did not show pronounced differences between the species.

\section{Anatomical cross-sectional area}

Absolute values for ACSA for the four specimens analyzed can be found in Table 4. The relative ACSA of all muscles 
a

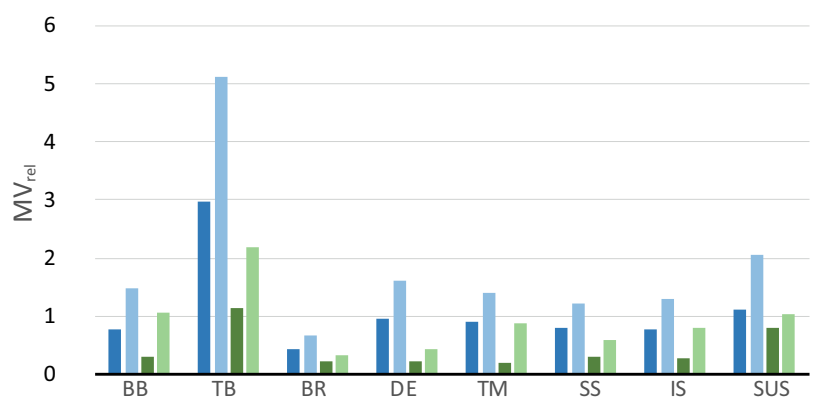

c

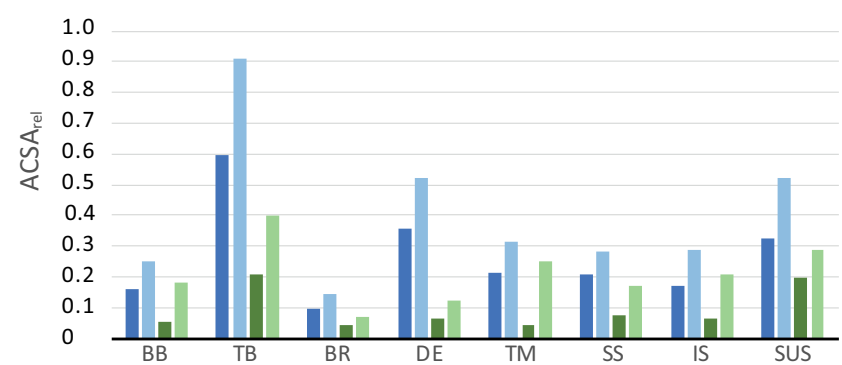

e

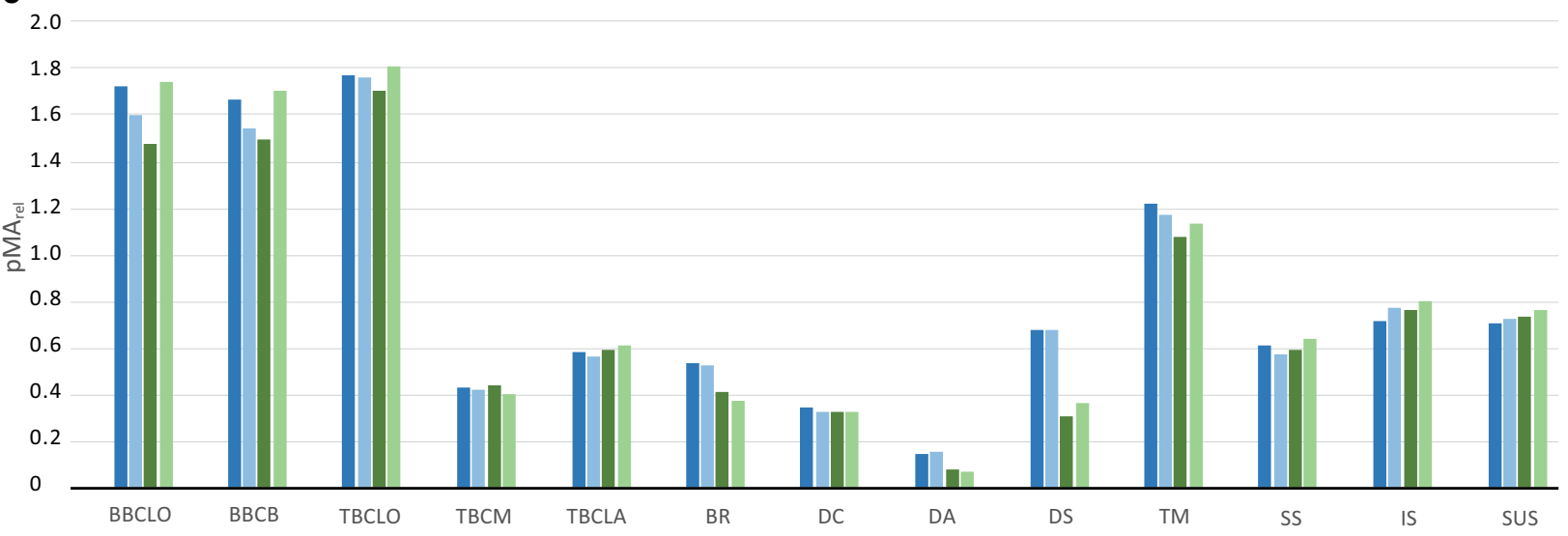

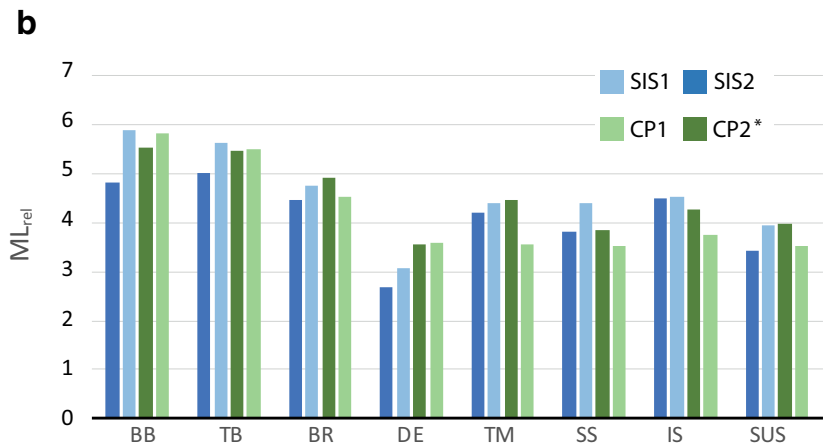

d

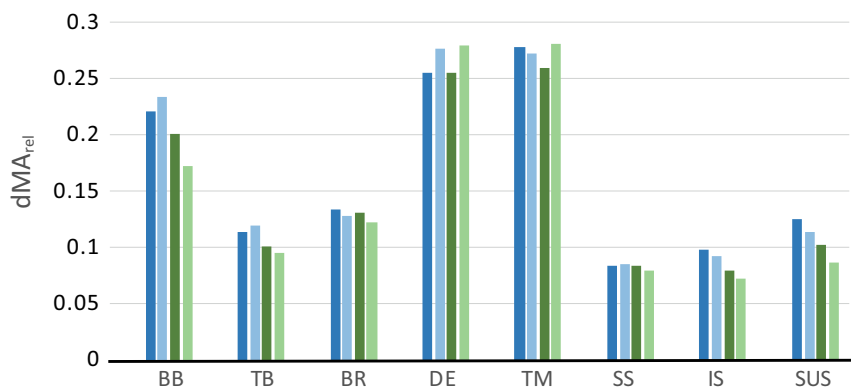

Fig. 7 Muscle architectural parameters of S. imperator and C. pygmaea a relative muscle volume $\left(\mathrm{MV}_{\text {rel }}\right)$, b relative muscle length $\left(\mathrm{ML}_{\text {rel }}\right)$, c relative ACSA (ACSA $\mathrm{Arl}_{\text {rel }}$, $\mathbf{d}$ distal relative moment arms $\left(\mathrm{dMA}_{\text {rel }}\right)$, e proximal relative moment arms $\left(\mathrm{pMA}_{\text {rel }}\right)$. BB: m. biceps brachii; BBCLO: biceps brachii caput longum; BBCB: biceps brachii caput breve; TB: m. triceps brachii; TBCLO: triceps brachii caput considered is approximately twice as large in $\mathrm{CP} 1$ as in $\mathrm{CP} 2$. The relative ACSA for biceps brachii, triceps brachii, brachialis, deltoideus, teres major, supraspinatus, infraspinatus, and subscapularis is slightly larger in SIS1 than in SIS2.

The relative ACSA for biceps brachii, brachialis, teres major, supraspinatus, infraspinatus, and subscapularis is three times larger in $S$. imperator than in $C$. pygmaea (Fig. 7). The relative ACSA for triceps brachii is twice as large in $C$. pygmaea as in $S$. imperator. For deltoideus, the longum; TBCM: triceps brachii caput mediale; TBCLA: triceps brachii caput laterale; BR: brachialis; DE: deltoideus; DC: deltoideus pars clavicularis; DA: deltoideus pars acromialis; DS: deltoideus pars spinalis TM: teres major; SS: supraspinatus; IS: infraspinatus; SUS: subscapularis

relative ACSA is three times larger in $S$. imperator than in C. pygmaea.

\section{Osteological muscle moment arms}

SIS1 has a slightly larger relative distal moment arm than SIS2 for biceps brachii, triceps brachii, and deltoideus (Table 5). For brachialis, teres major, infraspinatus, and subscapularis, the relative distal moment arm of SIS1 is smaller 


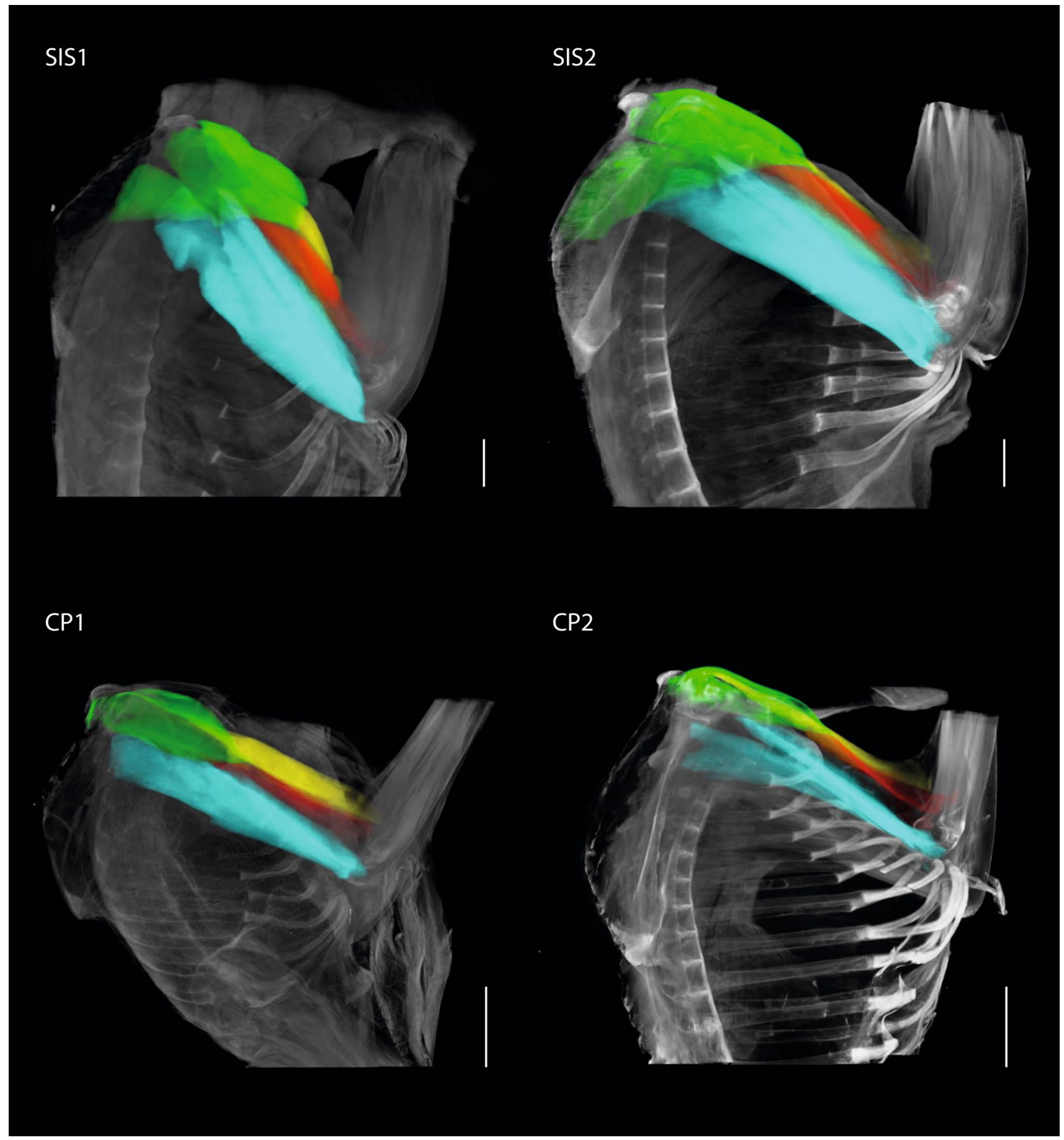

Fig. 8 Lateral view of the upper arm muscles of S. imperator and C. pygmaea. SIS1 and SIS2: S. imperator; CP1 and CP2: C. pygmaea; biceps brachii: yellow; triceps brachii: turquoise; brachialis: red; deltoideus: light green. Scale bar $=10 \mathrm{~mm}$

in comparison to SIS2. The relative distal moment arm of supraspinatus is the same in both individuals. CP1 has a slightly smaller distal relative moment arm for biceps brachii, triceps brachii, brachialis, supraspinatus, infraspinatus, and subscapularis than CP2. For deltoideus and teres major, $\mathrm{CP} 1$ has a slightly larger relative moment arm than $\mathrm{CP} 2$.
The relative proximal moment arm for biceps brachii caput longum and caput breve and for teres major is slightly larger in SIS2 than in SIS1. For the other muscles examined in this study the relative proximal moment arm is approximately the same in both specimens of $S$. imperator. The relative proximal moment arm for biceps brachii caput longum and 


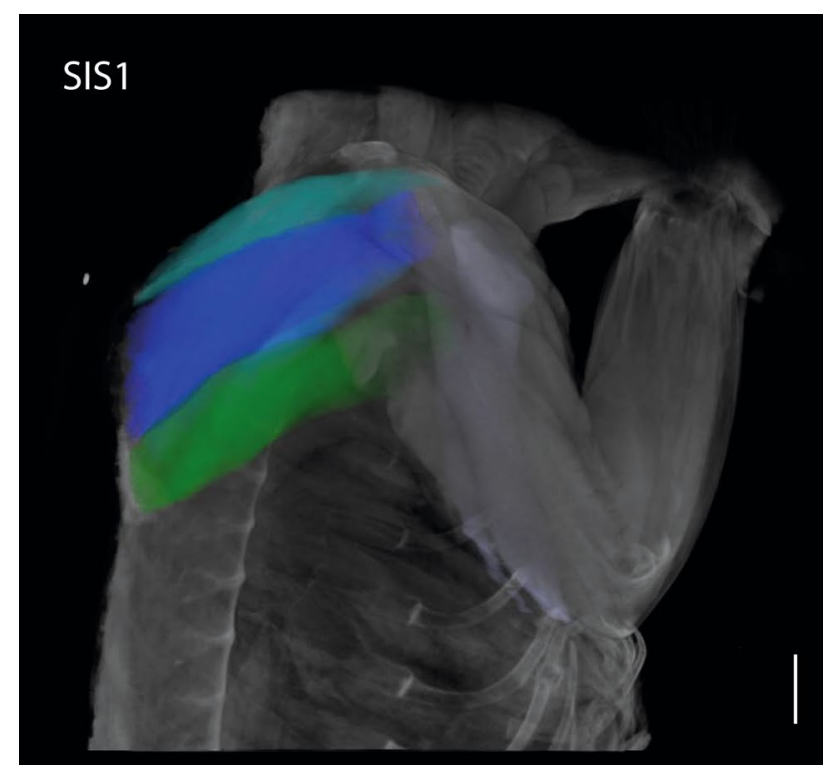

\section{SIS2}
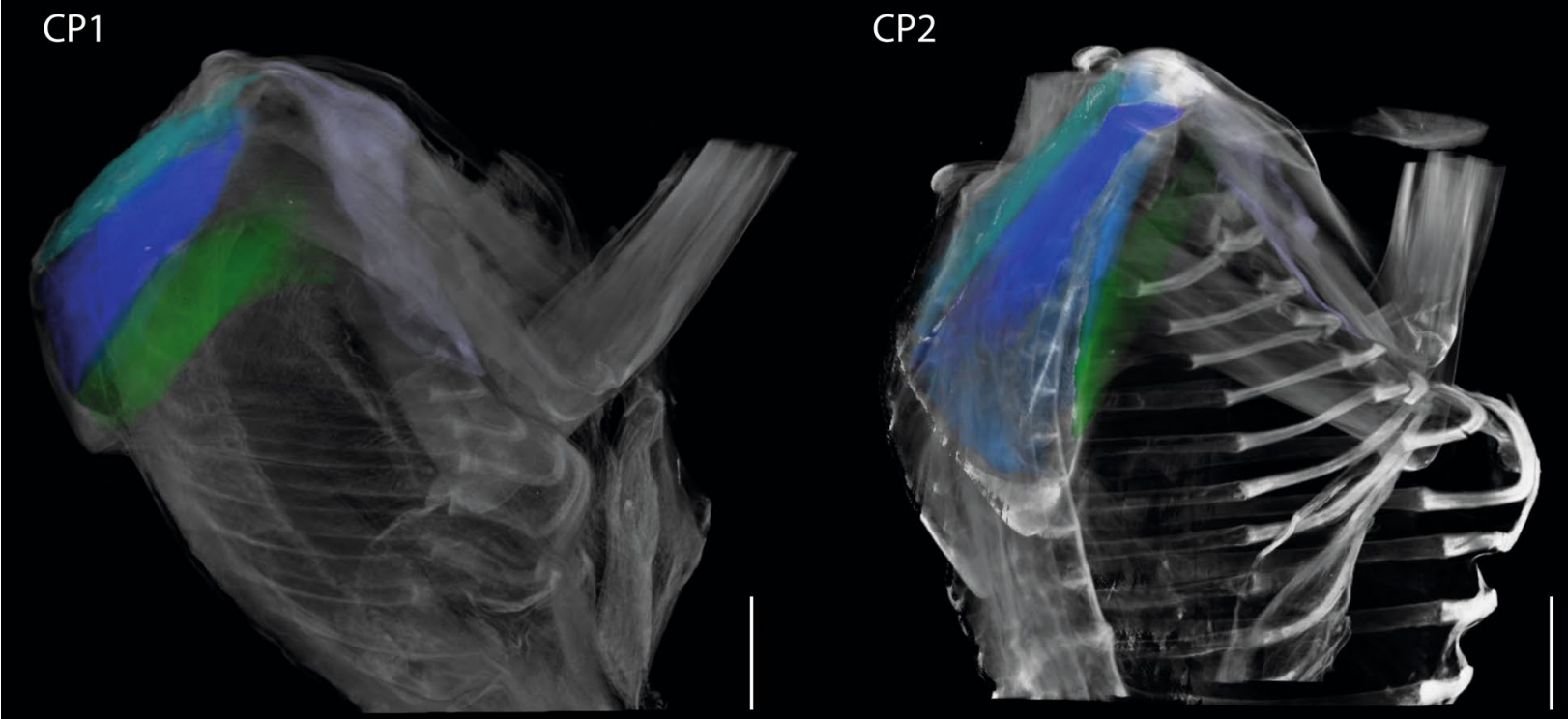

Fig. 9 Lateral view of the shoulder muscles of $S$. imperator and $C$. pygmaea. SIS1 and SIS2: S. imperator; $\mathrm{CP} 1$ and $\mathrm{CP} 2$ : C. pygmaea; supraspinatus: dark turquoise; infraspinatus: blue; teres major: dark

caput breve, triceps brachii caput longum, deltoideus pars spinalis, teres major, and supraspinatus is slightly larger in $\mathrm{CP} 1$ than in $\mathrm{CP} 2$. For the other muscles, the relative proximal moment arm is approximately the same in both specimens of $C$. pygmaea.

The relative distal moment arm is slightly larger in $S$. imperator for biceps brachii, triceps brachii, infraspinatus, and subscapularis in comparison to C. pygmaea. For brachialis, deltoideus, teres major, and supraspinatus the specimens green; pectoralis major: purple (due to damage not analyzed in this study). Scale bar $=10 \mathrm{~mm}$

do not exhibit pronounced differences. The relative proximal moment arm is larger in S. imperator for deltoideus pars acromialis and pars spinalis in comparison to C. pygmaea. For the other muscles, the relative proximal moment arm is approximately the same in both species. 
Table 3 Muscle length in $\mathrm{mm}$ (ML) and in relation to the average body mass ${ }^{0.33}$ of the corresponding species $\left(\mathrm{ML}_{\mathrm{rel}}\right)$

\begin{tabular}{llcccc}
\hline Muscle & & SIS1 & SIS2 & CP1 & CP2* \\
\hline Biceps brachii & $\mathrm{ML}$ & 45.9 & 37.6 & 31.0 & 29.5 \\
& $\mathrm{ML}_{\text {rel }}$ & 5.89 & 4.82 & 5.84 & 5.55 \\
Triceps brachii & $\mathrm{ML}$ & 43.9 & 39.2 & 29.3 & 29.2 \\
& $\mathrm{ML}_{\text {rel }}$ & 5.63 & 5.02 & 5.51 & 5.49 \\
Brachialis & $\mathrm{ML}$ & 37.1 & 34.8 & 24.1 & 26.2 \\
& $\mathrm{ML}_{\text {rel }}$ & 4.75 & 4.45 & 4.54 & 4.93 \\
Deltoideus & $\mathrm{ML}$ & 24.0 & 20.9 & 19.0 & 18.9 \\
& $\mathrm{ML}_{\text {rel }}$ & 3.08 & 2.68 & 3.58 & 3.55 \\
Teres major & $\mathrm{ML}$ & 34.4 & 32.9 & 19.0 & 23.8 \\
Supraspinatus & $\mathrm{ML}_{\text {rel }}$ & 4.41 & 4.21 & 3.57 & 4.48 \\
& $\mathrm{ML}$ & 34.3 & 29.9 & 18.7 & 20.4 \\
Infraspinatus & $\mathrm{ML}_{\text {rel }}$ & 4.39 & 3.83 & 3.52 & 3.84 \\
& $\mathrm{ML}^{\text {Subscapularis }}$ & 35.4 & 35.1 & 20.0 & 22.8 \\
& $\mathrm{ML}_{\text {rel }}$ & 4.54 & 4.50 & 3.76 & 4.29 \\
& $\mathrm{ML}$ & 30.7 & 26.9 & 18.8 & 21.1 \\
& $\mathrm{ML}_{\text {rel }}$ & 3.94 & 3.44 & 3.54 & 3.97 \\
\hline
\end{tabular}

*Atrophied specimen marked with an asterisk

Table 4 ACSA of muscles in $\mathrm{mm}^{2}$ (ACSA) and in relation to the average body mass ${ }^{0.66}$ of the corresponding species $\left(\mathrm{ACSA}_{\mathrm{rel}}\right)$

\begin{tabular}{llrrrr}
\hline Muscle & & SIS1 & SIS2 & CP1 & CP2* \\
\hline Biceps brachii & ACSA & 15.28 & 9.87 & 5.13 & 1.53 \\
& ACSA $_{\text {rel }}$ & 0.25 & 0.16 & 0.18 & 0.05 \\
Triceps brachii & ACSA & 55.33 & 36.12 & 11.26 & 5.89 \\
& ACSA $_{\text {rel }}$ & 0.91 & 0.59 & 0.40 & 0.21 \\
Brachialis & ACSA & 8.59 & 5.89 & 1.99 & 1.22 \\
& ACSA $_{\text {rel }}$ & 0.14 & 0.10 & 0.07 & 0.04 \\
Deltoideus & ACSA & 31.61 & 21.71 & 3.48 & 1.48 \\
Teres major & ACSA $_{\text {rel }}$ & 0.52 & 0.36 & 0.12 & 0.07 \\
& ACSA $_{\text {Supraspinatus }}$ & 19.26 & 13.00 & 7.01 & 1.17 \\
& ACSA $_{\text {rel }}$ & 0.32 & 0.21 & 0.25 & 0.04 \\
& ACSA $_{\text {Infraspinatus }}$ & 17.02 & 12.66 & 4.80 & 2.17 \\
& ACSA $_{\text {rel }}$ & 0.28 & 0.21 & 0.17 & 0.08 \\
Subscapularis & ACSA & 17.34 & 10.40 & 5.92 & 1.82 \\
& ACSA $_{\text {rel }}$ & 0.28 & 0.17 & 0.21 & 0.06 \\
& ACSA & 31.77 & 19.86 & 8.17 & 5.59 \\
& ACSA $_{\text {rel }}$ & 0.52 & 0.33 & 0.29 & 0.20 \\
\hline
\end{tabular}

*Atrophied specimen marked with an asterisk

\section{Discussion}

Through a comparison of two species of callitrichid primate species faced with differing functional demands, the aim of this study was to provide incipient comparative data for the investigation of the relationship between the properties of the shoulder and brachial muscles, the muscle moment arms, and locomotor ecology. Contrast-enhanced $\mu \mathrm{CT}$ was used to visualize the muscles and to quantify functionally relevant parameters of the musculoskeletal system in a limited sample of primate specimens.

\section{Gross morphology}

Functional specialization, such as a specialization to a specific locomotor mode like HL or TTL studied here, could result in changed positions of muscle attachment sites, which will alter potential muscle excursion (e.g., Lautenschlager 2015; Regnault et al. 2020) and muscle moment arms (e.g., Michilsens et al. 2009; Regnault et al. 2017). Overall, the muscle attachment sites are similar for $S$. imperator and C. pygmaea. Interspecific differences are observed in teres major and deltoideus, which leads to differences in moment arms for these muscles.

In relation to the species' average body mass, $S$. imperator is characterized by very large muscle volumes. This is consistent with the assumption that $S$. imperator has comparatively larger and more powerful muscles due to its locomotor behavior (Leischner et al. 2018; Marchi et al. 2018). In S. imperator the triceps brachii has a relative volume twice as large as that of $C$. pygmaea, suggesting that in HL this muscle has a more significant role than in TTL. This muscle plays a crucial role as an anti-gravity muscle and mainly counteracts gravity-induced limb flexion in pronograde postures (Jacobs et al. 1993; Fischer and Blickhan 2006). It can also be expected to contribute to the dissipation of impact forces by becoming stretched after landing when the limb is flexed.

Of all the muscles examined, the greatest interspecific difference can be observed in the deltoideus and the teres major. For these muscles the relative muscle volume of $S$. imperator is four times larger than in C. pygmaea. The teres major plays a crucial role in climbing and serves as a humerus retractor (Argot 2001; Larson and Stern 1986; Toledo 2013). Relatively, $S$. imperator seems to invest more into this muscle than C. pygmaea. A strong teres major, which is important for humeral retraction, seems to be beneficial for horizontal leaping. The lower relative muscle volume in $C$. pygmaea potentially is linked to the TTL behavior, since an increase in body weight, which would be associated with a larger muscle volume, impairs locomotor capabilities on vertical surfaces following the argumentation of Karantanis (2010), as it becomes more difficult to counteract gravity in a vertical clinging position the heavier an animal gets. Also, the larger relative muscle volume in $S$. imperator may be related to the larger role of the forelimbs for the generation of propulsion during quadrupedal locomotion on moderately inclined surfaces, which has been demonstrated for similar sized cotton-top tamarins (Hesse 
Table 5 Osteological muscle moment arms in mm (MA) and in relation to the length of the connecting skeletal element $\left(\mathrm{MA}_{\mathrm{rel}}\right)$ for the distal (dMA) and the proximal (pMA) moment arm

\begin{tabular}{|c|c|c|c|c|c|}
\hline \multicolumn{2}{|l|}{ Muscle } & SIS1 & SIS2 & CP1 & $\mathrm{CP} 2 *$ \\
\hline \multicolumn{6}{|l|}{ Distal osteological muscle moment arms (dMA) } \\
\hline \multirow[t]{2}{*}{ Biceps brachii to radius } & dMA & 9.97 & 8.86 & 5.42 & 6.86 \\
\hline & $\mathrm{dMA}_{\text {rel }}$ & 0.23 & 0.22 & 0.17 & 0.20 \\
\hline \multirow[t]{2}{*}{ Triceps brachii to ulna } & dMA & 6.19 & 5.61 & 3.45 & 3.93 \\
\hline & $\mathrm{dMA}_{\text {rel }}$ & 0.12 & 0.11 & 0.10 & 0.10 \\
\hline \multirow[t]{2}{*}{ Brachialis to ulna } & dMA & 6.63 & 6.60 & 4.41 & 5.15 \\
\hline & $\mathrm{dMA}_{\text {rel }}$ & 0.13 & 0.13 & 0.12 & 0.13 \\
\hline \multirow[t]{2}{*}{ Deltoideus to humerus } & dMA & 14.14 & 11.77 & 9.80 & 9.70 \\
\hline & $\mathrm{dMA}_{\text {rel }}$ & 0.28 & 0.26 & 0.28 & 0.26 \\
\hline \multirow[t]{2}{*}{ Teres major to humerus } & dMA & 13.90 & 12.84 & 9.84 & 9.90 \\
\hline & $\mathrm{dMA}_{\text {rel }}$ & 0.27 & 0.28 & 0.28 & 0.26 \\
\hline \multirow[t]{2}{*}{ Supraspinatus to humerus } & dMA & 4.43 & 3.89 & 2.78 & 3.22 \\
\hline & $\mathrm{dMA}_{\text {rel }}$ & 0.09 & 0.08 & 0.08 & 0.08 \\
\hline \multirow[t]{2}{*}{ Infraspinatus to humerus } & dMA & 4.70 & 4.56 & 2.57 & 3.02 \\
\hline & $\mathrm{dMA}_{\text {rel }}$ & 0.09 & 0.10 & 0.07 & 0.08 \\
\hline \multirow[t]{2}{*}{ Subscapularis to humerus } & dMA & 5.80 & 5.79 & 3.06 & 3.89 \\
\hline & $\mathrm{dMA}_{\text {rel }}$ & 0.11 & 0.13 & 0.09 & 0.10 \\
\hline \multicolumn{6}{|c|}{ Proximal osteological muscle moment arm (pMA) } \\
\hline \multirow[t]{2}{*}{ Biceps brachii caput longum to scapula } & pMA & 48.75 & 43.39 & 32.03 & 35.20 \\
\hline & $\mathrm{pMA}_{\text {rel }}$ & 1.60 & 1.72 & 1.74 & 1.48 \\
\hline \multirow[t]{2}{*}{ Biceps brachii caput breve to scapula } & pMA & 47.01 & 42.09 & 31.32 & 35.55 \\
\hline & $\mathrm{pMA}_{\text {rel }}$ & 1.55 & 1.67 & 1.70 & 1.49 \\
\hline \multirow[t]{2}{*}{ Triceps brachii caput longum to scapula } & pMA & 46.68 & 41.79 & 33.49 & 35.20 \\
\hline & $\mathrm{pMA}_{\mathrm{rel}}$ & 1.76 & 1.77 & 1.81 & 1.70 \\
\hline \multirow[t]{2}{*}{ Triceps brachii caput mediale to humerus } & pMA & 21.55 & 19.82 & 14.19 & 16.54 \\
\hline & $\mathrm{pMA}_{\text {rel }}$ & 0.42 & 0.43 & 0.41 & 0.44 \\
\hline \multirow[t]{2}{*}{ Triceps brachii caput laterale to humerus } & pMA & 28.73 & 26.65 & 21.44 & 22.64 \\
\hline & $\mathrm{pMA}_{\text {rel }}$ & 0.56 & 0.58 & 0.61 & 0.60 \\
\hline \multirow[t]{2}{*}{ Brachialis to humerus } & pMA & 26.69 & 24.44 & 13.11 & 15.60 \\
\hline & $\mathrm{pMA}_{\text {rel }}$ & 0.52 & 0.53 & 0.37 & 0.41 \\
\hline \multirow[t]{2}{*}{ Deltoideus to clavicula } & pMA & 8.46 & 8.51 & 5.35 & 6.07 \\
\hline & $\mathrm{pMA}_{\text {rel }}$ & 0.32 & 0.35 & 0.32 & 0.33 \\
\hline \multirow[t]{2}{*}{ Deltoideus to acromium } & pMA & 4.14 & 3.56 & 1.14 & 1.69 \\
\hline & $\mathrm{pMA}_{\mathrm{rel}}$ & 0.15 & 0.14 & 0.06 & 0.08 \\
\hline \multirow[t]{2}{*}{ Deltoideus to spina } & pMA & 18.85 & 16.70 & 6.35 & 6.41 \\
\hline & $\mathrm{pMA}_{\text {rel }}$ & 0.68 & 0.68 & 0.36 & 0.31 \\
\hline \multirow[t]{2}{*}{ Teres major to scapula } & pMA & 32.59 & 30.03 & 21.10 & 21.07 \\
\hline & $\mathrm{pMA}_{\text {rel }}$ & 1.18 & 1.22 & 1.14 & 1.07 \\
\hline \multirow[t]{2}{*}{ Supraspinatus to scapula } & pMA & 15.79 & 14.88 & 11.31 & 12.22 \\
\hline & $\mathrm{pMA}_{\mathrm{rel}}$ & 0.57 & 0.61 & 0.64 & 0.59 \\
\hline \multirow[t]{2}{*}{ Infraspinatus to scapula } & pMA & 21.38 & 17.64 & 14.13 & 15.71 \\
\hline & $\mathrm{pMA}_{\text {rel }}$ & 0.77 & 0.72 & 0.80 & 0.76 \\
\hline \multirow[t]{2}{*}{ Subscapularis to scapula } & pMA & 20.13 & 17.23 & 13.44 & 15.20 \\
\hline & $\mathrm{pMA}_{\text {rel }}$ & 0.73 & 0.70 & 0.76 & 0.73 \\
\hline
\end{tabular}

*Atrophied specimen marked with an asterisk et al. 2015). More comparative data is needed to assess these trends quantitatively.

\section{Muscle architecture}

The ACSA is the ratio of the muscle volume to the muscle's 
length. A relatively (to body mass) large ACSA is an indicator of muscles that can generate a lot of force. The relative ACSA of the muscles is larger in S. imperator than in $C$. pygmaea (Fig. 7). The biggest differences can be observed for triceps brachii and deltoideus, which are forelimb extensors and important on horizontal or declining supports, e.g., head-first postures, as well as during jumping and to dissipate energy with the forelimbs during landing, which appears to be more important for horizontal leapers. Muscles with a small ACSA (not taking into account the confounding factor of potential differences in fascicle lengths) also reduce the mass of the front limb and thereby suggest the capability for rapid joint rotation during powerful movements that might be advantageous for certain locomotor tasks, such as vertical climbing and leaping.

The relative muscle lengths did not differ between the species analyzed in this study, suggesting that muscle length is not affected by preferred locomotor behavior.

\section{Osteological muscle moment arms}

Moment arms together with force generated by a muscle determine the torque acting at a joint (Channon et al. 2010). The quantitative description of moment arms is essential to understanding the function of the musculoskeletal system (Murray et al. 2002; Ackland et al. 2008; Channon et al 2010). The larger the moment arm, the greater the torque that can be generated, but the lower the speed of joint movement (Lieber and Fridén 2001; Channon et al. 2010). This very general pattern is also dependent on contraction speed, which is determined by fascicle length but not captured in ACSA (e.g., Lieber and Fridén 2001; Allen et al. 2010). The forelimb muscles of sloths are an extreme example where moment arms are maximized and locomotor speed is limited (Fujiwara et al. 2011; Nyakatura and Fischer 2011).

The only difference in relative distal moment arm is observed for biceps brachii and triceps brachii. The relative distal moment arm is slightly larger in $S$. imperator than in C. pygmaea. For relative proximal moment arm, the only difference is observed for deltoideus pars acromialis and pars spinalis. The relative moment arm for these muscles is twice as large in S. imperator as in C. pygmaea. These differences in moment arms suggest a larger importance of counterbalancing arm flexion during landing for these muscles.

The relative distal moment arms of triceps brachii, brachialis, supraspinatus, infraspinatus, and subscapularis and the relative proximal moment arms of triceps brachii caput mediale, triceps brachii caput laterale, deltoideus pars clavicularis, deltoideus pars acromialis, deltoideus pars spinalis, supraspinatus, infraspinatus, and subscapularis are small in both species examined compared to the rest of the examined muscles, which suggests that these muscles might have a stabilizing function in the shoulder muscles (Ackland et al. 2008). In addition, a small moment arm increases a muscle's working range (Channon et al. 2010). The large relative distal moment arms of biceps brachii, deltoideus, and teres major and the relative proximal of biceps brachii, triceps brachii caput longum, and teres major in both species characterize these muscles as prime movers and suggest that they are not suitable for rapid movements during jumping, but to generate great forces. For example, Payne et al. (2006) have shown that instantaneous muscle moment arms increase with increasing joint flexion, a finding which may be understood in the context of employment of more crouched and compliant postures during arboreal locomotion (Schmitt 1999). A predominant role in stability in fact may not be reflected in the lengths of moment arms, but for example in fiber-type composition which was not assessed here.

\section{Limitations}

A limitation of this study may be the small number of available individuals. This limits the expressiveness of intraspecific differences, since musculoskeletal differences between two individuals could theoretically be traced back to illnesses or an age-related decrease in muscles. The agerelated decrease in musculature and the associated decrease in muscle strength was observed in all mammals that were examined for age-related changes (Faulkner et al. 2007, 2008). The specimens did not show obvious signs of disease or illness. Nevertheless, one specimen appeared to be atrophied (CP2). We marked the specimen with an asterisk in all graphs and tables and considered potentially flawed muscle volume and ACSA data for this specimen in the discussion.

In both wild and captive animals, age is usually accompanied by a decrease in grip strength (Hamalainen et al. 2015). The analyzed subjects stem from a captive breeding group, which can have an influence on the pattern of food intake and on locomotor behavior related to predator avoidance. The absence of such ecological pressures allows older individuals to maintain their health longer than would be possible in the wild. Accordingly, animals kept in captivity often develop a locomotor repertoire that differs from that of their wild counterparts (Crompton et al. 2003). Finally, we cannot rule out that the muscle tissue, due to the long storage time in alcohol and the treatment with contrast media, has shrunk (Cutts 1988; Vickerton et al. 2013; Buytaert et al. 2014). Signs of this include that the volumes of the bones of CP2 are larger than in CP1, but the volumes of the muscles are smaller. In addition, a few superficial muscles of CP2 and SIS2 appeared to be damaged by freezer burn (Table. 1). We acknowledge that differences in anatomy cannot be attributed to functional requirements alone, but also other factors like age, and training condition might have an influence. Sexual dimorphism might also be a factor but is 
not common in small platyrrhine primates and therefore not taken into account in this study (e.g., Kappeler 1990; Ford 1994). Nevertheless, we believe that the general patterns that we describe here are reflective of the species' adaptiveness to their differing ecology, and the comparison of such closely related species may thus provide us with tentative insight into the functional adaption of these primates. The advent of algorithms that allow more automated segmentation (e.g., Dickinson et al. 2018; Nyakatura et al. 2019) and availability of even higher-resolution $\mu \mathrm{CT}$ imaging could alleviate the time-consuming manual segmentation of CT images and could provide an avenue towards the comparative analysis of larger and more inclusive datasets.

\section{Conclusion}

We examined the functional relationship between the properties of the musculoskeletal system of the shoulder and the locomotor behavior in the vertical clinger and leaper C. pygmaea and in $S$. imperator, a species that prefers horizontal locomotion. Despite the acknowledged limitations, the following conclusions can tentatively be drawn. Compared to $S$. imperator, $C$. pygmaea has muscles that are relatively small in volume. A low muscle mass might be advantageous for the long episodes of clinging to tree trunks involved in exudate feeding. The shoulder muscles of $S$. imperator, however, due to its relatively larger volume, are suited for the generation of larger forces. This might be beneficial for leaping from terminal branches that also involve the generation of thrust in the forelimbs. Although the moment arms do not differ very much between the two species, our results demonstrate that the preferred locomotor mode is reflected in the properties of the musculoskeletal system.

Since thrust for the jump is largely generated by the muscles of the hind limbs (Marchi et al. 2018), studies of the hind limb muscles and the length and orientation of the muscle fibers would be of great interest and could provide information about the functional differentiation of foreand hindlimbs in arboreal locomotion. An examination of additional callitrichid primate species could yield improved insight into the morphofunctional adaptations within the clade.

Acknowledgements The authors wish to thank Peter Galbusera and Maj Deckx of the Royal Zoological Society of Antwerp (RZSA) for providing specimens and Kristin Mahlow of the Museum für Naturkunde Berlin (MfN) for scanning the specimens analyzed in this study. The authors are grateful for helpful critique of two anonymous reviewers, for help with specimen preparation from Patricia Berles and for insightful discussions with Jan Wölfer. JAN acknowledges funding by the German Research Foundation (grant no.: DFG NY 63/2-1).

Funding Open Access funding enabled and organized by Projekt DEAL.
Open Access This article is licensed under a Creative Commons Attribution 4.0 International License, which permits use, sharing, adaptation, distribution and reproduction in any medium or format, as long as you give appropriate credit to the original author(s) and the source, provide a link to the Creative Commons licence, and indicate if changes were made. The images or other third party material in this article are included in the article's Creative Commons licence, unless indicated otherwise in a credit line to the material. If material is not included in the article's Creative Commons licence and your intended use is not permitted by statutory regulation or exceeds the permitted use, you will need to obtain permission directly from the copyright holder. To view a copy of this licence, visit http://creativecommons.org/licenses/by/4.0/.

\section{References}

Ackland DC, Pak P, Richardson M, Pandy MG (2008) Moment arms of the muscles crossing the anatomical shoulder. J Anat 213:383-390

Allen V, Elsey RM, Jones N, Wright J, Hutchinson JR (2010) Functional specialization and ontogenetic scaling of limb anatomy in Alligator mississippiensis. J Anat 216(4):423-445

Anapol F, Barry K (1996) Fiber architecture of the extensors of the hindlimb in semiterrestrial and arboreal guenons. Am J Phys Anthropol: off Publ Am Assoc Phys Anthropol 99:429-447

Argot C (2001) Functional-adaptive anatomy of the forelimb in the Didelphidae, and the paleobiology of the Paleocene marsupials Mayulestes ferox and Pucadelphys andinus. J Morphol 247(1):51-79

Buchanan-Smith HM, Hardie SM, Caceres C, Prescott MJ (2000) Distribution and forest utilization of Saguinus and other primates of the Pando Department, northern Bolivia. Int J Primatol 21(3):353-379

Buckner JC, Lynch Alfaro JW, Rylands AB, Alfaro ME (2015) Biogeography of the marmosets and tamarins (Callitrichidae). Mol Phylogenet Evol 82:413-425. https://doi.org/10.1016/j.ympev. 2014.04.031

Buytaert J, Goyens J, De Greef D, Aerts P, Dirckx J (2014) Volume shrinkage of bone, brain and muscle tissue in sample preparation for micro-CT and light sheet fluorescence microscopy (LSFM). Microsc Microanal 20:1208-1217. https://doi.org/10.1017/S1431 927614001329

Cartmill M, Hildebrand M, Bramble DM, Liem KF, Wake DB (1985) Functional vertebrate morphology. Harvard University Press, Cambridge, MA

Channon AJ, Crompton RH, Günther MM, Vereecke EE (2010) Muscle moment arms of the gibbon hind limb: implications for hylobatid locomotion. J Anat 216:446-462

Crompton RH, Thorpe S, Weijie W, Yu L, Payne R, Savage R, Carey T, Aerts P, Van Elsacker L, Hofstetter A, Günther M, Richardson J (2003) The biomechanical evolution of erect bipedality. CourierForschungsinstitut Senckenberg 243:135-146

Cutts A (1988) Shrinkage of muscle fibres during the fixation of cadaveric tissue. J Anat 160:75

Demes B, Fleagle J, Lemelin P (1998) Myological correlates of prosimian leaping. J Hum Evol 34:385-399

Descamps E, Sochacka A, De Kegel B, Van Loo D, Van Hoorebeke L, Adriaens D (2014) Soft tissue discrimination with contrast agents using micro-CT scanning. Belgian Journal of Zoology 144(1):20-40

Dickinson E, Stark H, Kupczik K (2018) Non-destructive determination of muscle architectural variables through the use of DiceCT. Anat Rec 301(2):363-377 
Faulkner JA, Larkin LM, Claflin DR, Brooks SV (2007) Age-related changes in the structure and function of skeletal muscles. Clin Exp Pharmacol Physiol 34:1091-1096

Faulkner JA, Davis CS, Mendias CL, Brooks SV (2008) The aging of elite male athletes: age-related changes in performance and skeletal muscle structure and function. Clin J Sport Med: off J Can Acad Sport Med 18:501

Fischer MS, Blickhan R (2006) The tri-segmented limbs of therian mammals: kinematics, dynamics, and self-stabilization-a review. J Exp Zool 305A:935-952

Fleagle JG, Meldrum DJ (1988) Locomotor behavior and skeletal morphology of two sympatric pitheciine monkeys, Pithecia pithecia and Chiropotes satanas. Am J Primatol 16:227-249

Fleagle JG, Mittermeier RA (1980) Locomotor behavior, body size, and comparative ecology of seven Surinam monkeys. Am J Phys Anthropol 52:301-314

Ford SM (1994) Evolution of sexual dimorphism in body weight in platyrrhines. Am J Primatol 34(2):221-244

Fujiwara SI, Endo H, Hutchinson JR (2011) Topsy-turvy locomotion: biomechanical specializations of the elbow in suspended quadrupeds reflect inverted gravitational constraints. J Anat 219(2):176-191

Gans C, Bock WJ (1965) The functional significance of muscle architecture-a theoretical analysis. Ergeb Anat Entwicklungsgesch 38:115-142

Garber PA (1980) Locomotor behavior and feeding ecology of the Panamanian tamarin (Saguinus oedipus geoffroyi, Callitrichidae, Primates). Int J Primatol 1:185-201

Garber PA (1991) A comparative study of positional behavior in three species of tamarin monkeys. Primates 32:219-230

Garber PA, Pruetz J (1995) Positional behavior in moustached tamarin monkeys: effects of habitat on locomotor variability and locomotor stability. J Hum Evol 28:411-426

Garber PA, Sussman RW (1984) Ecological distinctions between sympatric species of Saguinus and Sciurus. Am J Phys Anthropol 65:135-146

Hamalainen A, Dammhahn M, Aujard F, Kraus C (2015) Losing grip: senescent decline in physical strength in a small-bodied primate in captivity and in the wild. Exp Gerontol 61:54-61

Hesse B, Nyakatura JA, Fischer MS, Schmidt M (2015) Adjustments of limb mechanics in cotton-top tamarins to moderate and steep support orientations: significance for the understanding of early primate evolution. J Mamm Evol 22:435-450. https://doi.org/ 10.1007/s10914-014-9283-4

Hunt KD, Cant JG, Gebo DL, Rose MD, Walker SE, Youlatos D (1996) Standardized descriptions of primate locomotor and postural modes. Primates 37:363-387

Huq E, Wall CE, Taylor AB (2015) Epaxial muscle fiber architecture favors enhanced excursion and power in the leaper Galago senegalensis. J Anat 227:524-540. https://doi.org/10.1111/joa. 12351

Ikai M, Fukunaga T (1968) Calculation of muscle strength per unit cross-sectional area of human muscle by means of ultrasonic measurement. Inte Zeitschrift Für Angewandte Physiol Einschliesslich Arbeitsphysiol 26(1):26-32

Jacobs R, Bobbert MF, Van Ingen Schenau GJ (1993) Function of mono- and biarticular muscles in running. Med Sci Sports Exerc 25:1163-1173

Kappeler PM (1990) The evolution of sexual size dimorphism in prosimian primates. Am J Primatol 21(3):201-214

Karantanis NE (2010) Comparative positional behaviour in three captive callitrichid species: Leontopithecus chrysomelas, Saguinus imperator and Cebuella pygmaea. MSc Thesis, University College of London

Kikuchi Y (2010) Comparative analysis of muscle architecture in primate arm and forearm. Anat Histol Embryol 39:93-106
Kinzey WG, Rosenberger AL, Ramirez M (1975) Vertical clinging and leaping in a neotropical anthropoid. Nature 255:327

Koç MM, Aslan N, Kao AP, Barber AH (2019) Evaluation of X-ray tomography contrast agents: a review of production, protocols, and biological applications. Microsc Res Tech 82(6):812-848

Larson SG (2015) Rotator cuff muscle size and the interpretation of scapular shape in primates. J Hum Evol 80:96-106

Larson SG, Stern JT Jr (1986) EMG of scapulohumeral muscles in the chimpanzee during reaching and "arboreal" locomotion. Am J Anat 176(2):171-190

Larson SG, Stern JT Jr (2006) Maintenance of above-branch balance during primate arboreal quadrupedalism: coordinated use of forearm rotators and tail motion. Am J Phys Anthropol: off Publ Am Assoc Phys Anthropol 129(1):71-81

Larson SG, Stern JT Jr (2013) Rotator cuff muscle function and its relation to scapular morphology in apes. J Hum Evol 65(4):391-403

Lautenschlager S (2015) Estimating cranial musculoskeletal constraints in theropod dinosaurs. Royal Soc Open Sci 2(11):150495

Leischner CL, Crouch M, Allen KL, Marchi D, Pastor F, Hartstone-Rose A (2018) Scaling of primate forearm muscle architecture as it relates to locomotion and posture. Anat Rec 301:484-495

Lieber RL, Fridén J (2000) Functional and clinical significance of skeletal muscle architecture. Muscle Nerve 23:1647-1666

Lieber RL, Fridén J (2001) Clinical significance of skeletal muscle architecture. Clin Orthop Relat Res 1976-2007(383):140-151

Lieber RL, Jacobson MD, Fazeli BM, Abrams RA, Botte MJ (1992) Architecture of selected muscles of the arm and forearm: anatomy and implications for tendon transfer. The Journal of Hand Surgery 17:787-798

Marchi D, Leischner CL, Pastor F, Hartstone-Rose A (2018) Leg muscle architecture in primates and its correlation with locomotion patterns. Anat Rec (Hoboken) 301:515-527. https://doi.org/10.1002/ar.23745

Méndez J (1960) Density and composition of mammalian muscle. Metabolism 9:184-188

Metscher BD (2009a) MicroCT for comparative morphology: simple staining methods allow high-contrast 3D imaging of diverse nonmineralized animal tissues. BMC Physiol 9(1):11

Metscher BD (2009b) MicroCT for developmental biology: a versatile tool for high-contrast 3D imaging at histological resolutions. Dev Dyn: off Publ Am Assoc Anat 238:632-640

Michilsens F, Vereecke EE, D'août K, Aerts P (2009) Functional anatomy of the gibbon forelimb: adaptations to a brachiating lifestyle. J Anat 215(3):335-354

Murray WM, Buchanan TS, Delp SL (2002) Scaling of peak moment arms of elbow muscles with upper extremity bone dimensions. J Biomech 35:19-26

Nadjafzadeh MN, Heymann EW (2008) Prey foraging of red titi monkeys, Callicebus cupreus, in comparison to sympatric tamarins, Saguinus mystax and Saguinus fuscicollis. Am J Phys Anthropol 135:56-63

Nyakatura JA, Fischer MS (2011) Functional morphology of the muscular sling at the pectoral girdle in tree sloths: convergent morphological solutions to new functional demands? J Anat 219(3):360-374

Nyakatura JA, Heymann EW (2010) Effects of support size and orientation on symmetric gaits in free-ranging tamarins of Amazonian Peru: implications for the functional significance of primate gait sequence patterns. J Hum Evol 58:242-251

Nyakatura JA, Baumgarten R, Baum D, Stark H, Youlatos D (2019) Muscle internal structure revealed by contrast-enhanced $\mu \mathrm{CT}$ and fibre recognition: the hindlimb extensors of an arboreal and a fossorial squirrel. Mamm Biol 99(1):71-80

Olson RA, Glenn ZD, Cliffe RN, Butcher MT (2018) Architectural properties of sloth forelimb muscles (Pilosa: Bradypodidae). J Mamm Evol 25(4):573-588

Pauwels E, Van Loo D, Cornillie P, Brabant L, Van Hoorebeke L (2013) An exploratory study of contrast agents for soft tissue visualization 
by means of high resolution X-ray computed tomography imaging. J Microsc 250:21-31

Payne RC et al (2006) Morphological analysis of the hindlimb in apes and humans. I. Muscle architecture. J Anat 208:709-724

Peres CA (1993) Notes on the primates of the Juruá River, western Brazilian Amazonia. Folia Primatol 61:97-103

Prost JH (1965) A definitional system for the classification of primate locomotion. Am Anthropol 67:1198-1214

Regnault S, Allen VR, Chadwick KP, Hutchinson JR (2017) Analysis of the moment arms and kinematics of ostrich (Struthio camelus) double patellar sesamoids. J Exp Zool 327:163-171

Regnault S, Fahn-Lai P, Norris RM, Pierce SE (2020) Shoulder muscle architecture in the echidna (Monotremata: Tachyglossus aculeatus) indicates conserved functional properties. J Mamm Evol 13:1-13

Roberts D (1974) Structure and function of the primate scapula. Primate locomotion. New York, Academic Press, 171-200

Rosin S, Nyakatura JA (2017) Hind limb extensor muscle architecture reflects locomotor specialisations of a jumping and a striding quadrupedal caviomorph rodent. Zoomorphology 136:267-277

Rupert JE, Rose JA, Organ JM, Butcher MT (2015) Forelimb muscle architecture and myosin isoform composition in the groundhog (Marmota monax). J Exp Biol 218(2):194-205

Schmidt M (2011) Locomotion and postural behaviour. Adv Sci Res 5:23-39

Schmitt D (1999) Compliant walking in primates. J Zool 248(2):149-160

Schmitt D (2003) Substrate size and primate forelimb mechanics: implications for understanding the evolution of primate locomotion. Int J Primatol 24:1023-1036

Schumacher GH (1961) Funktionelle Morphologie der Kaumuskulatur. Jena, Fischer, 262

Smith RJ, Jungers WL (1997) Body mass in comparitive primatology. J Hum Evol 32:523-559

Stafford BJ, Rosenberger AL, Beck BB (1994) Locomotion of free-ranging golden lion tamarins (Leontopithecus rosalia) at the National Zoological Park. Zoo Biol 13:333-344
Taverne M, Fabre AC, Herbin M, Herrel A, Peigné S, Lacroux C, Lowie A, Pagès F, Theil JC, Böhmer C (2018) Convergence in the functional properties of forelimb muscles in carnivorans: adaptations to an arboreal lifestyle? Biol J Lin Soc 125(2):250-263

Toledo N, Bargo MS, Vizcaíno SF (2013) Muscular reconstruction and functional morphology of the forelimb of early Miocene sloths (Xenarthra, Folivora) of Patagonia. The Anatomical Record 296(2):305-325

Vickerton P, Jarvis J, Jeffery N (2013) Concentration-dependent specimen shrinkage in iodine-enhanced micro CT. J Anat 223:185-193

Williams SB, Wilson AM, Rhodes L, Andrews J, Payne RC (2008) Functional anatomy and muscle moment arms of the pelvic limb of an elite sprinting athlete: the racing grehound (Canis familiaris). J Anat 213:361-372

Wölfer J, Amson E, Arnold P, Botton-Divet L, Fabre AC, van Heteren AH, Nyakatura JA (2019) Femoral morphology of sciuromorph rodents in light of scaling and locomotor ecology. J Anat 234:731-747

Youlatos D (1999) Positional behavior of Cebuella pygmaea in Yasuni National Park, Ecuador. Primates 40:543-550

Youlatos D (2009) Locomotion, postures, and habitat use by pygmy marmosets (Cebuella pygmaea). The smallest anthropoids. Springer, pp 279-297

Zajac FE (1992) How musculotendon architecture and joint geometry affect the capacity of muscles to move and exert force on objects: a review with application to arm and forearm tendon transfer design. The Journal of Hand Surgery 17:799-804

Zajac FE, Gordon ME (1989) Determining muscle's force and action in multi-articular movement. Exerc Sport Sci Rev 17:187-230

Publisher's Note Springer Nature remains neutral with regard to jurisdictional claims in published maps and institutional affiliations. 